\title{
Desempenho e digestibilidade aparente dos nutrientes em ovinos alimentados com dietas contendo bagaço de cana-de-açúcar tratado com óxido de cálcio ${ }^{1}$
}

\section{Rogério Mendes Murta ${ }^{2}$, Modesto Antônio Chaves ${ }^{3}$, Aureliano José Vieira Pires ${ }^{4}$, Cristina Mattos Veloso ${ }^{5}$, Fabiano Ferreira da Silva ${ }^{4}$, Aires Lima Rocha Neto ${ }^{6}$, Antônio Eustáquio Filho $^{6}$, Paulo Eduardo Ferreira dos Santos ${ }^{6}$}

\author{
1 Projeto financiado pelo Banco do Nordeste. \\ 2 Instituto Federal de Educação do Norte de Minas - Campus Salinas, MG. Doutorando em Zootecnia da Universidade Estadual do Sudoeste \\ da Bahia (UESB). \\ 3 UESB - Departamento de Estudos Básicos e Instrumentais. \\ ${ }^{4}$ UESB - Departamento de Tecnologia Rural e Animal. Bolsista do CNPq. \\ 5 UFV - Departamento de Zootecnia. Bolsista do CNPq. \\ ${ }^{6}$ Doutorando em Zootecnia da Universidade Estadual do Sudoeste da Bahia (UESB).
}

RESUMO - Foram estudados os efeitos da adição de 0,0;0,75; 1,5 e 2,25\% de óxido de cálcio no bagaço de cana-deaçúcar (com base na matéria natural) com o objetivo de avaliar o desempenho, o consumo de nutrientes e a digestibilidade aparente das dietas e dos nutrientes em ovinos mestiços da raça Santa Inês e raças nativas. Vinte e quatro ovinos, mantidos em total confinamento, foram distribuídos em delineamento inteiramente ao acaso, com quatro níveis de óxido de cálcio e seis repetições. Os animais foram mantidos em baias individuais, por 77 dias. Os primeiros 14 dias foram de adaptação e, então, seguiram-se três períodos de 21 dias de coleta de dados. Na determinação da digestibilidade, utilizou-se o método de coleta total de fezes, que foi realizada nos quatro últimos dias do período experimental. As fezes foram coletadas três vezes ao dia, às 7, 13 e 18 h. O uso do óxido de cálcio não influenciou os consumos de matéria seca, proteína bruta, fibra em detergente neutro, fibra em detergente ácido e nutrientes digestíveis totais, mas houve efeito linear sobre ganho de peso, com o aumento nas doses de óxido de cálcio, mas não sobre a conversão alimentar e os coeficientes de digestibilidade aparente da matéria seca, proteína bruta e fibra em detergente ácido. Entretanto, foi observado efeito quadrático para o coeficiente de digestibilidade aparente da fibra em detergente. A utilização do bagaço de cana hidrolisado com óxido de cálcio em níveis a partir de $1,5 \%$ da matéria natural promove melhoras no desempenho de ovinos e aumenta a digestibilidade apenas da fibra em detergente neutro.

Palavras-chave: nutrição, pequenos ruminantes, resíduo industrial

\section{Performance and nutrients apparent digestibility in sheep fed diets containing sugar cane bagasse treated with calcium oxide}

\begin{abstract}
The addition effects of $0.0 ; 0.75 ; 1.5$ and $2.25 \%$ of calcium oxide on sugar-cane bagasse (on natural matter basis) were studied to evaluate the performance, nutrients intake and apparent digestibility of the diets and nutrients in crossbred sheep of Santa Inês and native breeds. Twenty-four sheep, maintened in total confinement, were assigned in a completely randomized experimental design, with four levels of calcium oxide and six repetitions. Animals were kept in individual pens for 77 days. The first 14 days were for animals adaptation and three periods of 21 days of data collection. The method of total fecal collection was used to estimate digestibility, which was carried in four days at the end of the experimental period. Feces were collected three times a day, at $7 \mathrm{am}, 1$ and $6 \mathrm{pm}$. The intake of dry matter, crude protein, neutral detergent fiber, acid detergent fiber and total digestible nutrients were not influenced by the use of calcium oxide. There was a linear effect in daily weight gain with increasing calcium oxide dose. However, there was no treatment effect on feed conversion and apparent digestibility coefficients of dry matter, crude protein and acid detergent fiber. Whereas the quadratic effect was observed for neutral detergent fiber apparent digestibility coefficient. The use of the hydrolized sugar cane bagasse with calcium oxide, from 1.5\%, promote increase in performance of sheep and increase digestibility in neutral detergent fiber.
\end{abstract}

Key Words: industrial residue, nutrition, small ruminant

Recebido em 28/8/2009 e aprovado em 5/7/2010.

Correspondências devem ser enviadas para: rogerio.murta@ifnmg.edu.br 


\section{Introdução}

A redução do custo de produção em produtos de origem animal tem sido direcionada para a utilização racional de todos os recursos alimentares disponíveis. Considerando que a atividade pecuária é de custo elevado, o setor produtivo vem buscando alternativas de fontes alimentares de menor custo.

Há grande disponibilidade de resíduos agroindustriais no Brasil, que podem e devem ser utilizados, evitando inclusive problemas ambientais. São aproximadamente 130 milhões de toneladas de subprodutos gerados anualmente. Desses subprodutos, uma grande diversidade pode ser utilizada na alimentação de ruminantes (Pires et al., 2002).

A produção estacional de forragem é um fato concreto, que tem causado enormes prejuízos à pecuária, pois a maioria dos produtores não se prepara para suplementar os rebanhos no período de escassez. A moagem da cana-de-açúcar e consequente produção do bagaço acontece justamente nesse período crítico, no qual falta alimento para os animais, ocorrendo, na maioria das vezes, perda de peso.

O uso do bagaço de cana-de-açúcar na alimentação animal é viabilizado com o uso de tratamentos que permitiram melhorar a sua digestibilidade. Alguns agentes alcalinizantes têm sido usados para melhorar a digestibilidade por meio da hidrólise. Desses, o composto químico mais recentemente utilizado é o óxido de cálcio.

A digestão pode ser definida como um processo de conversão de macromoléculas dos nutrientes em compostos mais simples, que podem ser absorvidos no trato gastrintestinal. Medidas de digestibilidade servem para qualificar os alimentos quanto ao seu valor nutritivo e são expressas pelo coeficiente de digestibilidade, indicando a quantidade percentual de cada nutriente do alimento que o animal potencialmente pode aproveitar (Van Soest, 1994). De acordo com Cardoso et al. (2000), o principal objetivo em determinar o valor nutricional dos alimentos é, ajustar a quantidade e qualidade da dieta, baseando-se nas exigências dos animais.

Apesar da grande quantidade de bagaço de cana-deaçúcar produzida no Brasil, ainda são escassas as informações disponíveis com relação à utilização e aos tratamentos adequados deste resíduo para alimentação de ruminantes, bem como respostas de desempenho animal.

Objetivou-se com este trabalho avaliar o uso de doses de óxido de cálcio na hidrólise do bagaço de cana-de-açúcar e seus efeitos no desempenho de ovinos confinados e determinar os coeficientes de digestibilidade aparente da matéria seca, proteína bruta, fibra em detergente neutro e fibra em detergente ácido das dietas.

\section{Material e Métodos}

O experimento foi conduzido no Setor de Ovinocaprinocultura do Instituto Federal de Educação do Norte de Minas Gerais - campus Salinas, Minas Gerais, e no Laboratório de Forragicultura e Pastagem da Universidade Estadual do Sudoeste da Bahia, UESB, em Itapetinga, Bahia, no período de setembro a dezembro de 2006.

Foram utilizados 24 ovinos machos não-castrados, mestiços da raça Santa Inês, com idade variando de 90 a 120 dias e peso corporal (PC) médio de $14 \mathrm{~kg} \pm 4,5 \mathrm{~kg}$, distribuídos em baias individuais. As baias, de 2,0 $\mathrm{m}^{2}$ cada, eram cobertas, possuíam piso ripado de madeira e eram providas de comedouros e bebedouros individuais. O delineamento experimental foi inteiramente casualisado, com quatro níveis de óxido de cálcio e seis repetições.

As dietas foram formuladas à base de milho e farelo de soja e continham bagaço de cana-de-açúcar sem óxido de cálcio ou hidrolisado com 0,$75 ; 1,5$ ou 2,25\% de óxido de cálcio na matéria natural do bagaço. O óxido de cálcio utilizado apresentou a seguinte composição química: 0,4\% $\mathrm{MgO} ; 0,3 \% \mathrm{Al}_{2} \mathrm{O}_{3} ; 1,4 \% \mathrm{SiO}_{2} ; 0,2 \% \mathrm{Fe}_{2} \mathrm{O}_{3} ; 87,3 \%$ de óxido de cálcio disponível; 0,07\% S (Christófaro, 2001). O bagaço de cana-de-açúcar utilizado foi fornecido pela fábrica de cachaça do Instituto Federal de Educação do Norte de Minas Gerais - campus Salinas, Minas Gerais.

O experimento teve duração de 77 dias, sendo 14 dias para adaptação dos animais às instalações e às dietas experimentais e três períodos de 21 dias para coleta de dados. No início do período de adaptação, as baias e os animais foram identificados, pesados, vermifugados (ivermectina e albendazol), receberam complexo vitamínico ADE via intramuscular e, após sorteio, foram distribuídos nos quatro níveis de óxido de cálcio. Durante esse período, foram feitos ajustes de consumo, que consistiram de pesagem do alimento fornecido e das sobras, com acréscimo de $10 \%$ do total fornecido no dia anterior.

Os animais receberam dietas, com base na matéria seca (MS), contendo $50 \%$ de bagaço de cana-de-açúcar e $50 \%$ de concentrado, com a mesma formulação para todos os tratamentos. A dieta total apresentou a seguinte composição: bagaço (50\%), milho (24\%), farelo de soja (24\%) e ureia (2\%).

As dietas foram calculadas para ser isoproteicas e isoenergéticas e conter nutrientes suficientes para ganho de 225 g/dia, de acordo com o NRC (1985), com base nos dados de composição química do bagaço de cana-de-açúcar com e sem hidrólise (Tabela 2). 
Tabela 1 - Composição dos ingredientes das dietas experimentais, com base na matéria seca

\begin{tabular}{|c|c|c|c|c|c|c|}
\hline \multirow[t]{2}{*}{ Item } & \multirow[t]{2}{*}{ Milho } & \multirow[t]{2}{*}{ Farelo de soja } & \multicolumn{4}{|c|}{ Óxido de cálcio no bagaço de cana (\%) } \\
\hline & & & 0,0 & 0,75 & 1,5 & 2,25 \\
\hline Matéria seca & 86,5 & 88,1 & 92,7 & 92,5 & 92,6 & 92,8 \\
\hline Proteína bruta & 9,0 & 46,7 & 1,2 & 1,0 & 1,0 & 0,9 \\
\hline Nutrientes digestíveis totais & 85,6 & 81,0 & 46,7 & 47,1 & 48,7 & 51,1 \\
\hline Fibra em detergente neutro & 14,0 & 11,5 & 63,8 & 62,3 & 60,3 & 58,8 \\
\hline Hemicelulose & 3,6 & 6,1 & 14,4 & 13,7 & 14,6 & 17,2 \\
\hline Lignina & 0,4 & 0,1 & 11,7 & 11,2 & 11,0 & 10,6 \\
\hline
\end{tabular}

Tabela 2 - Composição das dietas experimentais, em \% da matéria natural (\%MN)

\begin{tabular}{|c|c|c|c|c|}
\hline \multirow[t]{2}{*}{ Componente } & \multicolumn{4}{|c|}{ Óxido de cálcio no bagaço de cana (\%) } \\
\hline & 0,0 & 0,75 & 1,50 & 2,25 \\
\hline Matéria seca (\%MS) & 93,2 & 93,1 & 93,2 & 93,3 \\
\hline Fibra em detergente neutro (\%MS) & 44,2 & 43,4 & 42,4 & 41,7 \\
\hline Fibra em detergente ácido (\%MS) & 30,9 & 30,5 & 29,0 & 27,0 \\
\hline Nutrientes digestíveis totais (\%MS) & 59,3 & 59,5 & 60,3 & 61,5 \\
\hline
\end{tabular}

O óxido de cálcio foi diluído em água na proporção de 0,5 kg para cada dois litros de água e distribuído sobre o bagaço de cana-de-açúcar com auxílio de um regador. O material foi mantido por um período de dez horas para que ocorresse o processo de hidrólise, antes de ser fornecido aos animais. Preparava-se uma quantidade para alimentar os animais por um período de dois dias.

Os animais receberam diariamente, às $7 \mathrm{~h} 30$ e 16h30, a ração total (bagaço + ração concentrada), enquanto a água e a mistura mineral ficaram à disposição. As quantidades fornecidas eram pesadas diariamente e ajustadas de acordo com o consumo dos animais, de maneira a proporcionar sobras diárias de aproximadamente $10 \%$.

A pesagem dos animais foi realizada no início do experimento e a cada 21 dias, sempre no mesmo horário, antes da primeira refeição, após jejum de dieta sólida de 16 horas. Ao completar 77 dias de período experimental, os animais foram pesados para obtenção do PC final, do ganho de peso diário e da conversão alimentar.

Durante a fase experimental, foram colhidas amostras diárias dos volumosos, do concentrado e das sobras, formando amostras compostas a cada 21 dias, que foram acondicionadas em sacos plásticos e armazenadas em freezer. Ao final do experimento, as amostras foram descongeladas à temperatura ambiente. Posteriormente, foram pré-secas em estufa com circulação forçada de ar a $55^{\circ} \mathrm{C}$, por 72 horas, sendo, então, realizada a moagem utilizando peneira de malha de $1 \mathrm{~mm}$ para posteriores análises laboratoriais.
As análises de matéria seca, matéria mineral, nitrogênio total, celulose, hemicelulose e lignina foram realizadas segundo procedimentos descritos por Silva \& Queiroz (2005). As análises de fibra em detergente neutro e fibra em detergente ácido foram determinadas em aparelho autoclave, seguindo recomendações de Pell \& Schofield (1993).

O teor dos nutrientes digestíveis totais do bagaço de cana-de-açúcar foi estimado a partir da equação NDT = $74,49-0,5635 *$ FDA $\left(r^{2} 0,84\right)$, descrita por Cappelle et al. (2001) para volumosos.

Para obtenção dos coeficientes de digestibilidade aparente da matéria seca, proteína bruta, fibra em detergente neutro e fibra em detergente ácido, utilizou-se o método de coleta total de fezes. As fezes foram colhidas após o término do período de desempenho, ou seja, a partir do 78oㅡ dia após o início do experimento, durante quatro dias consecutivos, três vezes ao dia, às 7,13 e $18 \mathrm{~h}$, em bolsas de napa adaptadas aos animais. Depois de coletadas, as fezes foram pesadas, fazendo-se amostragem de uma alíquota correspondente a $10 \%$ do total excretado por animal. Após a amostragem, o material foi acondicionado em sacos plásticos devidamente identificados, fechados e armazenados em freezer $(-5$ a $-10^{\circ} \mathrm{C}$ ). Posteriormente, as amostras foram descongeladas, pré-secas em estufa com circulação forçada de ar a $55^{\circ} \mathrm{C}$, por 72 horas, sendo realizada a moagem com peneira de malha de $1 \mathrm{~mm}$, para posteriores análises laboratoriais.

Para determinação do coeficiente de digestibilidade da matéria seca, proteína bruta, fibra em detergente neutro e 
fibra em detergente ácido das dietas, utilizou-se a equação descrita por Schneider \& Flatt (1975):

$$
\mathrm{CD}=\frac{\text { (nutriente ingerido }- \text { nutriente excretado })}{\text { nutriente ingerido }} \times 100
$$

Os dados foram submetidos a análises de variância e de regressão a 5\% de probabilidade, em função das doses de óxido de cálcio no bagaço de cana-de-açúcar, por intermédio do Sistema de Análises Estatísticas e Genéticas - SAEG (Ribeiro Junior, 2001).

\section{Resultados e Discussão}

Não foi verificado efeito $(\mathrm{P}>0,05)$ das doses de óxido de cálcio utilizadas na hidrólise do bagaço de cana sobre o consumo de matéria seca. Esse fato pode ser explicado pelo teor de FDN das dietas, que apresentou pouca variação, confirmando as observações de Mertens (1992), que apontou a FDN como um dos principais fatores de controle do consumo de matéria seca. A redução no teor de FDN com o aumento do grau de hidrólise (Tabela 2) não foi suficiente para influenciar o consumo de MS dos animais.

Segundo Oliveira et al. (2008), a utilização de agentes alcalinos melhora a digestão da fibra, proporcionando maior consumo de MS. Os resultados encontrados neste trabalho com as doses de óxido de cálcio ( 0 a 2,25\%) não indicaram aumento do consumo de MS com a utilização desse agente alcalinizante.

Fadel et al. (2004), trabalhando com o resíduo do beneficiamento do arroz (palha) amonizado como volumoso exclusivo para ovinos confinados, observaram aumento do consumo com o tratamento da palha, sendo o consumo médio de 61,04 g/kg de peso metabólico (PM), inferior ao encontrado nesse trabalho (80,7 g/kg PM). Entretanto, o valor médio em \% do peso corporal (PC), 3,7\%, observado neste trabalho, foi inferior ao preconizado pelo o NRC (1985), de 5 e 4,3\% do PC para ovinos de 15 e $30 \mathrm{~kg}$, respectivamente. Todavia, está de acordo com os resultados encontrados por Barreto et al. (2004), que obtiveram valores médios de CMS de 3,8\% do PC para ovinos em confinamento recebendo dietas com relação volumoso:concentrado 40:60, contendo diferentes níveis de dejetos de suínos na ração concentrada.

A hidrólise do bagaço de cana-de-açúcar com óxido de cálcio não influenciou $(\mathrm{P}>0,05)$ o consumo de proteína bruta (PB), possivelmente em razão do baixo teor de PB do bagaço e pelo fato de que as dietas eram isoproteicas (20,2\% PB). O consumo de proteína bruta, expresso em g/dia, variou de 242,7 a 258,2. Para o CPB expresso em \% do PC, a variação foi de 1,07 a 1,1\% e em g/kg de PM variou de 23,5 a 24,1. Barreto et al. (2004) encontraram valores de consumo de $\mathrm{PB}$ variando de 0,71 a $0,8 \%$ do peso corporal e 16,68 a $18,53 \mathrm{~g} / \mathrm{kg}$ de $\mathrm{PM}$.

Segundo recomendações do NRC (1985), os valores médios de consumo de PB comprovam que as dietas experimentais supriram as exigências dos animais, mesmo para categorias mais exigentes, como é o caso dos animais deste trabalho. Estes resultados foram superiores aos encontrados por Lousada Junior et al. (2005), em ovinos sem raça definida, alimentados com subprodutos do processamento de frutas (abacaxi, acerola, goiaba, maracujá e melão).

Para o consumo de nutrientes digestíveis totais (NDT), também não se detectou efeito $(\mathrm{P}>0,05)$ pelos quatro níveis de óxido de cálcio no bagaço de cana-de-açúcar, o que pode ser explicado pela ausência de efeito no consumo de MS e pelo teor de NDT nas dietas, que não variou (Tabela 3). O consumo médio de NDT (569,2 g/dia) foi inferior ao preconizado pelo NRC (1985), de 750 e 1.000 g/dia, para

\begin{tabular}{|c|c|c|c|c|c|c|c|}
\hline \multirow[t]{2}{*}{ Variável } & \multicolumn{4}{|c|}{ Dose de óxido de cálcio (\% MN) } & \multirow[t]{2}{*}{ Regressão } & \multirow[t]{2}{*}{$\mathrm{r}^{2}$} & \multirow[t]{2}{*}{ CV $(\%)$} \\
\hline & 0,0 & 0,75 & 1,50 & 2,25 & & & \\
\hline Matéria seca (g/dia) & 820,8 & 830,6 & 870,0 & 887,8 & $\ddot{Y}=\hat{Y}=852,3$ & - & 9,9 \\
\hline Matéria seca (\% PC) & 3,7 & 3,6 & 3,7 & 3,8 & $\ddot{Y}=\hat{Y}=3,7$ & - & 7,0 \\
\hline Matéria seca (g/PM) & 79,6 & 79,5 & 80,9 & 83,0 & $\ddot{Y}=\hat{Y}=80,7$ & - & 5,6 \\
\hline Proteína bruta (g/dia) & 242,7 & 251,6 & 254,9 & 258,2 & $\ddot{Y}=\hat{Y}=251,8$ & - & 10,7 \\
\hline Proteína bruta (\% PC) & 1,08 & 1,10 & 1,07 & 1,09 & $\ddot{Y}=\hat{Y}=1,1$ & - & 6,6 \\
\hline Proteína bruta (g/PM) & 23,5 & 24,1 & 23,7 & 24,1 & $\ddot{Y}=\hat{Y}=23,8$ & - & 5,4 \\
\hline Nutrientes digestíveis totais (g/dia) & 543,7 & 555,2 & 579,6 & 598,8 & $\ddot{Y}=\hat{Y}=569,2$ & - & 10,0 \\
\hline Nutrientes digestíveis totais (\% PC) & 2,4 & 2,4 & 2,4 & 2,5 & $\ddot{Y}=\hat{Y}=2,5$ & - & 6,7 \\
\hline Nutrientes digestíveis totais (g/PM) & 52,7 & 53,1 & 53,9 & 55,9 & $\ddot{Y}=\hat{Y}=53,9$ & - & 5,1 \\
\hline Fibra em detergente neutro (g/dia) & 267,2 & 269,4 & 280,1 & 284,0 & $\ddot{Y}=\hat{Y}=272,9$ & - & 10,7 \\
\hline Fibra em detergente neutro (\% PC) & 1,2 & 1,1 & 1,2 & 1,2 & $\ddot{Y}=\hat{Y}=1,2$ & - & 9,0 \\
\hline Fibra em detergente neutro (g/PM) & 25,9 & 24,9 & 26,1 & 26,6 & $\ddot{Y}=\hat{Y}=29,9$ & - & 7,6 \\
\hline Fibra em detergente ácido (g/dia) & 170,1 & 163,2 & 172,8 & 164,3 & $\ddot{Y}=\hat{Y}=167,6$ & - & 11,0 \\
\hline Fibra em detergente ácido (\% PC) & 0,8 & 0,7 & 0,7 & 0,7 & $\ddot{Y}=\hat{Y}=0,7$ & - & 10,5 \\
\hline Fibra em detergente ácido (g/PM) & 16,5 & 15,6 & 16,1 & 15,4 & $\ddot{Y}=\hat{Y}=15,9$ & - & 9,0 \\
\hline
\end{tabular}

Tabela 3 - Consumo de nutrientes em função das doses de óxido de cálcio, na hidrólise do bagaço de cana-de-açúcar 
animais de 15 e $30 \mathrm{~kg}$, respectivamente. A qualidade do volumoso (bagaço) e o consumo de matéria seca possivelmente tiveram influência no consumo de NDT. Entretanto, Barreto et al. (2004) observaram valores inferiores aos encontrados neste trabalho (390 a 499 g/animal/dia), quando utilizaram dietas com valores de NDT próximos aos deste estudo.

Os consumos de fibra em detergente neutro (FDN) e fibra em detergente ácido (FDA) não diferiram $(\mathrm{P}>0,05)$ entre as dietas. Embora tenha ocorrido pequena redução dos teores de FDN e FDA com o aumento das doses de óxido de cálcio, essa diferença não foi expressa no consumo desses nutrientes. A ausência de efeito para o consumo de MS também colaborou para que não ocorresse efeito nos consumos de FDN e FDA.

O consumo de fibra em detergente neutro, em g/dia, \% do PC e g/kg de PM, variou de 267,2 a 284,0; 1,1 a 1,2 e 24,9 a 26,6, respectivamente, com as doses de óxido de cálcio na hidrólise do bagaço (0 a 2,25\%). Barreto et al. (2004) observaram valores variando de 35,82 a 44,25 g/kg de PM e de 1,61 a 1,91 \% do PC quando os valores de FDN na dieta variaram entre 47,3 a 52,6\%, valores superiores aos encontrados neste trabalho. Entretanto, o consumo de FDN foi semelhante ao proposto por Van Soest (1994), que está entre 0,8 e 1,2 \% do peso corporal. Esses resultados foram inferiores aos obtidos por Pires et al. (2004), que observaram valores médios de 530,0 g/dia, de 1,66\% do PC e de 39,26 g/ kg de PM, avaliando dietas com níveis de 0 e $30 \%$ de farelo de cacau na alimentação de ovinos Santa Inês.

O consumo de fibra em detergente ácido, em g/dia, \% do PC e g/kg de PM, variaram de 163,2 a 172,8 g/dia; 0,8 a $0,7 \%$ do PC e 16,5 a 15,4 g/kg de PM respectivamente, com as doses de óxido de cálcio na hidrólise do bagaço ( 0 a 2,25\%). Sousa (2005), testando níveis de inclusão de farelo de cacau (0, 7, 14 e 21\%) a um concentrado padrão, com valores de FDA próximos ao deste trabalho, observou média superior (353,5 g/dia) de CFDA. Essa diferença no CFDA pode estar relacionada ao alto teor de concentrado na dieta experimental (50\%), justificando, assim, o menor consumo de FDN e FDA.

No estudo de regressão, observou-se efeito linear crescente das doses de óxido de cálcio aplicadas na hidrólise do bagaço de cana sobre o ganho de peso no período (GPP). A cada $1 \%$ de inclusão de óxido de cálcio na hidrólise do bagaço, o ganho de peso no período aumentou 0,973 kg.

Os dados de GPP obtidos neste trabalho foram semelhantes aos encontrados por Cunha et al. (2008) em pesquisa com cordeiros Santa Inês alimentados com dietas contendo caroço de algodão. Sousa (2005), em experimento com ovinos alimentados com farelo de cacau, utilizando concentrado (30 a $40 \%$ da dieta) e dieta isoproteica ( $17 \%$ $\mathrm{PB})$, durante 70 dias de confinamento, obteve ganhos inferiores (7,11 a 10,47 kg de GPP) ao observado neste trabalho.

Os valores de ganho de peso diário (GPD) variaram de 195,0 a 229,9 g/animal/dia. Susin et al. (2000) relataram desempenhos superiores para ovinos Santa Inês e observaram GPD de $281 \mathrm{~g}$ /dia para cordeiros alimentados com rações contendo em torno de $80 \%$ de concentrado.

O estudo de regressão mostrou efeito linear crescente sobre o GPD dos animais, com o aumento nas doses de óxido de cálcio na hidrólise do bagaço de cana-de-açúcar. Os animais que receberam dietas com bagaço de cana-deaçúcar tratado com 1,5 e 2,25\% de óxido de cálcio apresentaram GPD superior ao esperado ( 225 g/dia). Vários fatores contribuíram para isso, entre eles, o teor de FDN $(63,8 \%)$ do bagaço de cana-de-açúcar utilizado, que foi inferior aos encontrados na literatura, o alto teor de concentrado na dieta, a seletividade dos animais e, também, a idade e o peso dos animais (14 kg, em média), pois, de acordo com a recomendação de Barros et al. (1994), para ganhos satisfatórios, os animais devem entrar no confinamento pesando de 15 a $18 \mathrm{~kg}$.

Cunha et al. (2008) observaram ganhos de peso superiores a $200 \mathrm{~g} / \mathrm{dia}$ em experimento com cordeiros recebendo dietas com relação volumoso:concentrado 60:40, tendo como volumoso feno de capim-tifton 85 e palmaforrageira. Yamamoto et al. (2005), avaliando ovinos Santa Inês puros e $1 \frac{1}{2}$ Dorset $+1 / 2$ Santa Inês alimentados com fontes de óleo vegetal, encontraram valores que variaram de 245 a $297 \mathrm{~g} /$ dia, superiores aos obtidos neste experimento; entretanto, os autores supracitados trabalharam com dietas contendo $60 \%$ ou mais de concentrado, proporção maior que a utilizada neste trabalho (50\%).

A conversão alimentar é definida pela quantidade de MS consumida para o ganho de $1 \mathrm{~kg}$ de peso corporal. Assim como para o consumo de MS, a conversão alimentar não foi influenciada $(\mathrm{P}>0,05)$ pelo tratamento do bagaço com óxido de cálcio. Apesar do efeito sobre o ganho de peso diário, esse não foi suficiente para influenciar a conversão alimentar, cujos valores variaram de 3,8 a 4,2 kg de MS para $1 \mathrm{~kg}$ de ganho de peso corporal (Tabela 4); esta conversão alimentar é consequência do bom GPD apresentado pelos animais.

É necessário observar o teor de FDN das dietas (Tabela 2), que foi baixo (44,2\%). Além disso, o alto teor de PB (20,2\%) na dieta influenciou a conversão alimentar. Cunha et al. (2008) encontraram conversão alimentar de 6,01 a 7,62 para ovinos Santa Inês alimentados com dietas contendo caroço de algodão e $40 \%$ de concentrado. Os dados encontrados 
neste trabalho também foram melhores que os encontrados por Barros et al. (1994), que relataram valor de 6,0 para cordeiros Santa Inês e também por Barreto et al. (2004), que encontraram valores variando de 5,59 a 5,88.

O coeficiente de digestibilidade aparente da matéria seca (CDMS) variou entre os quatro níveis de óxido de cálcio de 71,7 a 75,2\% e não apresentou diferenças significativas ( $\mathrm{P}>0,05)$ pelo estudo de regressão (Tabela 5). É importante salientar que, mesmo com a redução do teor de FDN com a adição do óxido de cálcio nas dietas, não houve alteração no coeficiente de digestibilidade aparente da MS. Cardoso et al. (2006) constataram redução na digestibilidade aparente total da MS para as rações com maiores teores de fibra. Entretanto, neste trabalho, não foi observada diferença significativa com a redução do teor de fibra (Tabela 1). Alves et al. (2003), trabalhando com uma relação volumoso:concentrado de 50:50 e com níveis crescentes de energia, observaram valor médio de 72,8\% de CDMS. Oliveira et al. (2007) constataram diferença significativa para a digestibilidade in vitro da MS (DIVMS) para o nível de $0,5 \%$ de óxido de cálcio em relação ao bagaço in natura e não observaram diferença entre os níveis de 0,5 e $1 \%$. Os valores de DIVMS variaram de 60,82 a 63,75\% e foram inferiores aos encontrados neste trabalho, evidenciando, no entanto, efeito do tratamento com o óxido de cálcio. Pires et al. (2006) avaliaram níveis crescentes $(0,0$ a 7,5\%) de hidróxido de sódio $(\mathrm{NaOH})$ na hidrólise do bagaço e observaram efeito quadrático sobre a DIVMS, relatando a solubilização parcial da hemicelulose e a expansão da celulose como justificativas para o aumento da DIVMS. Souza et al. (2004) observaram CDMS médio de 60,01\% em dietas contendo casca de café no concentrado, valor inferior ao encontrado neste trabalho, que pode ser justificado pelo teor de FDN das dietas experimentais.

O coeficiente de digestibilidade da proteína bruta (CDPB) foi semelhante entre os quatro níveis de óxido de cálcio ( $\mathrm{P}>0,05)$ e variou de $85,4 \%$ a 87,2\%. Segundo Cameron et al. (1991), a digestibilidade da PB aumenta com o teor de PB do alimento. Dessa forma, neste trabalho, os teores de PB não influenciaram o CDPB em razão das dietas serem isoproteicas e foram altos devido ao elevado teor de PB na dieta (20,2\%). Carvalho et al. (1995), ao justificarem o aumento da digestibilidade aparente da $\mathrm{PB}$, consideraram que, com aumento dos níveis de PB nas rações, houve redução do efeito do nitrogênio metabólico fecal sobre aquela fração. Souza et al. (2004) eEzequiel et al. (2005) relataram coeficientes de digestibilidade médios de 66,8 e 74,3\% da PB para dietas contendo casca de café e cana hidrolisada com $\mathrm{NaOH}$, respectivamente. Esses valores, que foram inferiores aos encontrados neste trabalho, são explicados pelo baixo teor de PB das dietas, que foi de $10 \%$. Alves et al. (2003), trabalhando com relação volumoso:concentrado de 50:50 e com níveis crescentes de energia, observaram valor médio de 77,6\% para o coeficiente de digestibilidade da PB.

Observou-se efeito quadrático da hidrólise do bagaço de cana sobre o coeficiente de digestibilidade aparente da fibra em detergente neutro (FDN), cujos valores variaram de $22,1 \%$ a $36,7 \%$. A dieta contendo bagaço tratado com $0,75 \%$ de óxido de cálcio apresentou maior digestibilidade e aquela contendo bagaço sem tratamento a menor (Figura 1). A digestibilidade da FDN pode ser influenciada pelo conteúdo de componentes da parede celular, além da própria estrutura

Tabela 4 - Desempenho de ovinos alimentados com dietas contendo bagaço de cana-de-açúcar hidrolisado com óxido de cálcio

\begin{tabular}{|c|c|c|c|c|c|c|c|c|}
\hline \multirow[t]{2}{*}{ Variável } & \multicolumn{4}{|c|}{ Dose de óxido de cálcio (\% MN) } & \multirow[t]{2}{*}{ Regressão } & \multirow[t]{2}{*}{$\mathrm{P}$} & \multirow[t]{2}{*}{$\mathrm{r}^{2}$} & \multirow[t]{2}{*}{$\mathrm{CV}(\%)$} \\
\hline & 0,0 & 0,75 & 1,50 & 2,25 & & & & \\
\hline Peso corporal inicial (kg) & 16,4 & 16,1 & 16,6 & 16,5 & - & - & - & - \\
\hline Ganho de peso no período $(\mathrm{kg})$ & 12,3 & 13,5 & 14,5 & 14,4 & $\hat{Y}=12,58+0,973 \mathrm{CaO}$ & 0,018 & 0,85 & 11,3 \\
\hline Ganho de peso diário (g) & 195,0 & 214,5 & 229,9 & 228,0 & $\hat{Y}=199,6+15,25 \mathrm{CaO}$ & 0,019 & 0,84 & 11,3 \\
\hline Conversão alimentar & 4,2 & 3,9 & 3,8 & 4,0 & $\ddot{Y}=\hat{Y}=4,0$ & - & - & 7,7 \\
\hline
\end{tabular}

$\mathrm{P}$ = nível de probabilidade; $\mathrm{r}^{2}$ = coeficiente de determinação; $\mathrm{CV}$ = coeficiente de variação.

Tabela 5 - Coeficientes de digestibilidade aparente (\%) das dietas experimentais

\begin{tabular}{|c|c|c|c|c|c|c|c|c|}
\hline \multirow[t]{2}{*}{ Variável } & \multicolumn{4}{|c|}{ Dose de óxido de cálcio (\%MN) } & \multirow{2}{*}{\multicolumn{2}{|c|}{ Regressão }} & \multirow[t]{2}{*}{$r^{2}$} & \multirow[t]{2}{*}{$\mathrm{CV}(\%$} \\
\hline & 0,0 & 0,75 & 1,50 & 2,25 & & & & \\
\hline Matéria seca & 71,8 & 75,2 & 71,7 & 72,9 & \multirow{4}{*}{$\hat{Y}=23,1+$} & $\hat{Y}=\ddot{Y}=72,9$ & - & 4,4 \\
\hline Proteína bruta & 87,2 & 87,0 & 85,4 & 87,2 & & $\hat{Y}=\ddot{Y}=86,7$ & - & 1,9 \\
\hline Fibra em detergente neutro & 22,1 & 36,7 & 33,4 & 32,3 & & $19,34 \mathrm{CaO}-6,977 \mathrm{CaO}^{2}$ & 0,83 & 23,1 \\
\hline Fibra em detergente ácido & 20,9 & 30,4 & 24,4 & 30,7 & & $\hat{Y}=\ddot{Y}=26,6$ & - & 31,5 \\
\hline
\end{tabular}

$\mathrm{r}^{2}$ = coeficiente de determinação; CV = coeficiente de variação. 


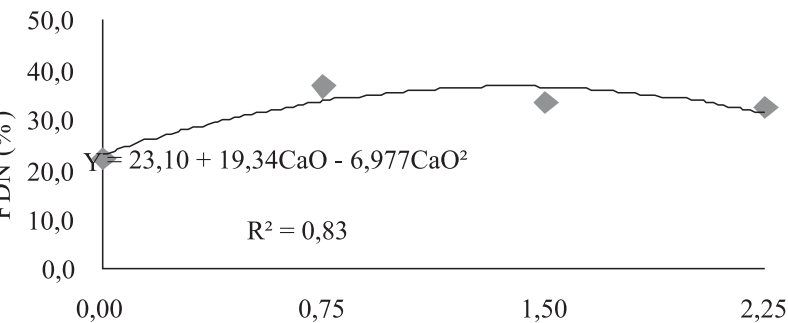

Dose de óxido de cálcio (\% da $\mathrm{MN})$

Figura 1 - Coeficiente de digestibilidade aparente da fibra em detergente neutro de dietas contendo bagaço de cana-de-açúcar tratado com óxido de cálcio.

e forma de organização. Como a relação volumoso e a proporção de concentrado nas dietas foram as mesmas, pode-se afirmar que as diferenças encontradas no coeficiente de digestibilidade da FDN são atribuídas à ação do óxido de cálcio solubilizando parte da parede celular (hemicelulose e celulose) do volumoso (bagaço), mostrando melhora na qualidade da FDN, corroborando com Van Soest (1994), que relatou como ação dos agentes alcalinos a solubilização de parte da parede celular dos volumosos de baixa qualidade, o que facilita o ataque dos microrganismos do rúmen à parede celular.

Alves et al. (2003) observaram coeficiente de digestibilidade de $59,71 \%$ da FDN, valor superior ao observado neste trabalho, e deve estar relacionado ao teor de FDN do volumoso utilizado (feno de capim-tifton), uma vez que a proporção volumoso:concentrado foi a mesma nos dois trabalhos. Oliveira et al. (2007) constataram valores de digestibilidade in vitro da fibra em detergente neutro (DIVFDN) variando entre 34,1 e 38,6\%, trabalhando com níveis de 0,0; 0,5 e 1,0\% de óxido de cálcio na hidrólise da cana. Souza et al. (2004) relataram média superior (46,9\%) para o coeficiente de digestibilidade da FDN quando utilizaram casca de café na dieta de ovinos. Esse valor, superior ao verificado neste trabalho, pode ser atribuído ao volumoso utilizado por esses autores (feno de Coastcross). Oliveira et al. (2008b) encontraram valores de 23,1 a 26,05\% para o coeficiente de digestibilidade in vitro da FDN da cana-de-açúcar tratada com 0,5 e 0,6\% de óxido de cálcio, respectivamente. Ezequiel et al. (2005) observaram coeficiente de digestibilidade da FDN de $65,4 \%$ para o bagaço tratado com $\mathrm{NaOH}$ na alimentação de bovinos mestiços (zebu $\times$ holandês) recebendo dieta com volumoso e concentrado na proporção 70:30.

O coeficientte de digestibilidade da fibra em detergente ácido (FDA) variou de 20,9 a 30,7\% quando as doses de óxido de cálcio na hidrólise do bagaço variaram de 0 a 2,25\%.
Não foi detectado efeito $(\mathrm{P}>0,05)$ sobre o coeficiente de digestibilidade da FDA, fato explicado pela pequena diferença no teor de FDA das dietas. Oliveira et al. (2007) constataram valores variando entre 30,9 e $33,6 \%$ para digestibilidade in vitro da FDA em pesquisa com níveis de 0,0; 0,5 e 1,0\% de óxido de cálcio na hidrólise da cana-deaçúcar e não notaram diferença entre as doses.

\section{Conclusões}

A dose de 2,25\% de óxido de cálcio utilizada na hidrólise do bagaço de cana-de-açúcar, mesmo não tendo afetado o consumo, proporciona maior ganho de peso diário em ovinos confinados, da ordem de 233,9 g/dia. A hidrólise com óxido de cálcio altera a digestibilidade apenas da fibra em detergente neutro, o que indica aumento da disponibilidade dos componentes da parede celular.

\section{Agradecimentos}

Ao Banco do Nordeste "ETENE/FUNDECI" pelo apoio financeiro. À Capes pela concessão da bolsa de mestrado.

\section{Referências}

OLIVEIRA, M.D.S.; BARBOSA, J.C.; MOTA, D.A. et al. Efeito da hidrólise com cal virgem sobre a composição bromatológica da cana-de-açúcar. Veterinária Noticías, v.14, n.1, p.19-27, 2008.

OLIVEIRA, M.D.S.; SANTOS, J.; DOMINGUES, F.N. et al. Avaliação da cal hidratada como agente hidrolisante de canade-açúcar. Veterinária Noticías, v.14, n.1, p.9-17, 2008 b.

CUNHA, M.G.G.; CARVALHO, F.F.R.; VÉRAS, A.S.C. et al. Desempenho e digestibilidade aparente em ovinos confinados alimentados com dietas contendo níveis crescentes de caroço de algodão integral. Revista Brasileira de Zootecnia, v.37, n.6, p.1103-1111, 2008.

CARDOSO, A.R.; PIRES, C.C.; CARVALHO, D. et al. Consumo de nutrientes e desempenho de cordeiros alimentados com dietas que contem diferentes níveis de fibra em detergente neutro. Ciência Rural, v.36, n.1, p.215-221, 2006.

ALVES, K.S.; CARVALHO, F.F.R.; CHAVES, A.S. et al. Níveis de energia em dietas para ovinos Santa Inês: Digestibilidade aparente. Revista Brasileira de Zootecnia, v.32, n.6, p.1962-1968, 2003 (supl. 3).

BARRETO, C.M.; AZEVEDO, A.R.; SALES, R.O. et al. Desempenho de ovinos em terminação alimentados com dietas contendo diferentes níveis de dejetos de suínos. Revista Brasileira de Zootecnia, v.33, n.6, p.1858-1865, 2004 (supl. 1).

BARROS, N.N.; FIGUEIREDO, E.A.P.; FERNANDES, F.D. et al. Ganho de peso e conversão alimentar de cordeiros cruzas no estado do Ceará. Pesquisa Agropecuária Brasileira, v.29, n.8, p.1313-1317, 1994.

CAMERON, M.R.; KLUSMEYER, T.H.; LYNCH, G.L. et al. Effects of urea and starch on rumen fermentation, nutrient passage to the duodenum, and performance of cows. Journal of Dairy Science, v.74, n.4, p.1321-1336, 1991.

CAPELLE, E.R.; VALADARES FILHO, S.C.; SILVA, J.F.C. et al. Estimativas do valor energético a partir de características químicas e bromatológicas dos alimentos. Revista Brasileira de Zootecnia, v.30, n.6, p.1837-1 856, 2001. 
CARDOSO, R.C.; VALADARES FILHO, S.C.; SILVA, J.F.C. da. et al. Consumo e digestibilidade aparentes totais e parciais de rações contendo diferentes níveis de concentrado, em novilhos F1 Limousin x Nelore. Revista Brasileira de Zootecnia, v.29, n.3, p.830-833, 2000.

CARVALHO, F.F.R.; QUEIROZ, A.C.; RODRIGUES, M.T. et al. Efeitos de níveis crescentes de proteína bruta sobre a digestibilidade dos nutrientes em cabras lactantes. Revista da Sociedade Brasileira de Zootecnia, v.24, p.852-862, 1995.

CHRISTÓFARO, A.G.G. Controle de qualidade. São José da Lapa: Itaú, 2001. 1p.

EZEQUIEL, J.M.B.; QUEIROZ, M.A.Á.; GALATI, R.L. et al. Processamento da cana-de-açúcar: Efeitos sobre a digestibilidade, o consumo e a taxa de passagem. Revista Brasileira de Zootecnia, v.34, n.5, p.1704-1710, 2005.

FADEL, R.; ROSA, B.; OLIVEIRA, I.P. Valor nutritivo da palha de arroz amonizada com ovinos. Ciência Animal Brasileira, v.5, n.1, p.19-25, 2004.

LOUSADA JR., J.E.; NEIVA, J.N.M.; RODRIGUEZ, N.M. et al. Consumo e digestibilidade aparente de subprodutos do processamento de frutas em ovinos. Revista Brasileira de Zootecnia, v.34, n.2, p.659-669, 2005.

MERTENS, D.R. Analysis of fiber in feeds and its uses in feed evaluation and ration formulation. In: SIMPÓSIO INTERNACIONAL DE RUMINANTES, REUNIÃO ANUAL DA SOCIEDADE BRASILEIRA DE ZOOTECNIA, 29., 1992, Lavras. Anais... Lavras: Sociedade Brasileira de Zootecnia, 1992. p.1-32.

NATIONAL RESEARCH COUNCIL - NRC. Nutrient requirements of sheep. 6.ed. Washington: National Academy Press, 1985. 99p.

OLIVEIRA, M.D.S.; QUEIROZ, M.A.A.; CALDEIRÃO, E. et al. Efeito da hidrólise com $\mathrm{NaOH}$ sobre a digestibilidade "in vitro" da matéria seca da cana-de-açúcar (Saccharum officinarum L.). Arquivo Brasileiro de Veterinária e Zootecnia, v.18, n.2, p.167-173, 2002.

OLIVEIRA, M.D.S.; ANDRADE, A.T.; BARBOSA, J.C. et al. Digestibilidade da cana-de-açúcar hidrolisada, in natura e ensilada para bovinos. Ciência Animal Brasileira, v.8, n.1, p.41-50, 2007.

OLIVEIRA, M.W.; BARBOSA, M.H.P.; MURILO, C. et al. Análise quantitativa do crescimento da variedade de cana-de-açúcar RB
72454. In: Encontro de Botânicos de MG, BA e ES, 23., 2001. Resumos... Viçosa, MG: UFV/SBB, 2001. v.1, p.89.

PELL, A.N.; SCHOFIELD, P. Computerized monitoring of gas production to measure forage digestion in vitro. Journal of Dairy Science, v.76, n.9, p.1063-1073, 1993.

PIRES, A.J.V.; REIS, R.A.; CARVALHO, G.G.P. et al. Bagaço de canade-açúcar tratado com hidróxido de sódio. Revista Brasileira de Zootecnia, v.35, n.3. p.953-957, 2006 (supl. 3).

PIRES, A.J.V.; VIEIRA, V.F.; SILVA, F.F. et al. Níveis de farelo de cacau (Teobroma cacao) na alimentação de novilhos. Disponível em: <http://www.reuniaoanualsbz.com.br/ conteudo/ Downloadtrabalho.asp?codigo=sbzo 11 46\& cpf6O9 1237560>4, 2002. Acesso em: 30/3/2007.

PIRES, A.J.V.; CARVALHO JUNIOR, J.N.; SILVA, F.F. et al. Farelo de cacau na alimentação de ovinos. Revista Ceres, v.51, n.293, p.33-43, 2004.

RIBEIRO JUNIOR, J.I. Análises estatísticas no SAEG (Sistema para análises estatísticas e genéticas). Viçosa, MG: UFV, 2001. 301p.

SCHNEIDER, B.H.; FLATT, W.P. The evaluation of feeds through digestibility experiments. Athens: University of Georgia Press, 1975. 423p

SILVA, D.J.; QUEIROZ, A.C. Análise de alimentos: métodos químicos e biológicos. 3.ed. Viçosa, MG: UFV; Imprensa Universitária, 2005. 235p.

SOUSA, F.G. Níveis crescente de farelo de cacau (Theobroma cacao L.) na alimentação de ovinos. 2005. 60f. Dissertação (Mestrado em Agronomia) - Universidade Estadual do Sudoeste da Bahia, Vitória da Conquista.

SOUZA, A.L.; GARCIA, R.; BERNARDINO, F.S. et al. Casca de café em dietas de carneiros: consumo e digestibilidade. Revista Brasileira de Zootecnia, v.33, n.6 p.2170-2176, 2004 (supl. 2).

SUSIN, I.; ROCHA, M.H.M.; PIRES, A.V. Efeito do uso do bagaço de cana-de-açúcar in natura ou hidrolisado sobre o desempenho de cordeiros confinados. In: REUNIÃO ANUAL DA SOCIEDADE BRASILEIRA DE ZOOTECNIA, 37., 2000 , Viçosa, MG. Anais... Viçosa, MG: SBZ, 2000. (CD-ROM).

VAN SOEST, P.J. Nutritional ecology of the ruminant. 2.ed. Ithaca: Cornell University Press, 1994. 476p.

YAMAMOTO, S.M.; MACEDO, F.A.F.; ZUNDT, M. et al. Fontes de óleo vegetal na dieta de cordeiros em confinamento. Revista Brasileira de Zootecnia, v.34, n.2, p.703-710, 2005. 